\title{
Online Social Skills Group Training for Adolescents and Young Adults with 22q11.2 Deletion Syndrome (22q11.2DS)
}

\author{
Bronwyn Glaser ${ }^{1 *}$, Stephan Eliez ${ }^{1,2}$, Hannah Cholemkery ${ }^{3}$, \\ Christine M. Freitag ${ }^{3}$, Maude Schneider ${ }^{1,4}$
}

\begin{abstract}
${ }^{1}$ Developmental Imaging and Psychopathology Lab, School of Medicine, University of Geneva, Geneva, Switzerland ${ }^{2}$ Department of Genetic Medicine and Development, School of Medicine, University of Geneva, Geneva, Switzerland ${ }^{3}$ Department of Child and Adolescent Psychiatry, Psychosomatics and Psychotherapy, University Hospital, Goethe University Frankfurt, Frankfurt, Germany

${ }^{4}$ Research Group Psychiatry, Department of Neurosciences, Center for Contextual Psychiatry, KU Leuven, Leuven, Belgium Email: *Bronwyn.glaser@unige.ch, Maude.Schneider@unige.ch
\end{abstract}

How to cite this paper: Glaser, B., Eliez, S., Cholemkery, H., Freitag, C.M. and Schneider, M. (2018) Online Social Skills Group Training for Adolescents and Young Adults with 22q11.2 Deletion Syndrome (22q11.2DS). Journal of Behavioral and Brain Science, 8, 126-145.

https://doi.org/10.4236/jbbs.2018.83008

Received: January 23, 2018

Accepted: March 25, 2018

Published: March 28, 2018

Copyright $\odot 2018$ by authors and Scientific Research Publishing Inc. This work is licensed under the Creative Commons Attribution International License (CC BY 4.0).

http://creativecommons.org/licenses/by/4.0/

\begin{abstract}
Somatic, cognitive and psychiatric obstacles contribute to social impairment in 22q11.2DS and prevent adequate responses during interactions. We adapted the autism-specific SOSTA-FRA program for use during online group sessions with geographically-isolated 22q11DS adolescents or adults. The 12 weekly sessions targeted communication, emotional awareness, and reciprocity. Twenty-two participants were evaluated on behaviour, social responsiveness, and cognition pre- and post-intervention. Parents completed a questionnaire to ascertain whether the intervention met their needs. Parents were satisfied with the format and curriculum contents and reported improved emotional awareness, well-being, and reciprocity post-intervention. Pre-post results suggest large effects on social awareness and small to medium effects on social motivation. Results indicate that online social skills training is feasible and effective for individuals with 22q11.2DS.
\end{abstract}

\section{Keywords}

Group, Social, 22q11.2 Deletion Syndrome, VCFS

\section{Introduction}

\subsection{Social Impairment in 22q11.2DS}

22q11.2 deletion syndrome (22q11.2DS), also known as velocardiofacial syndrome or DiGeorge syndrome, is a genetic disorder affecting at least 1:4000 live 
births [1]. While there is much variance in the extent to which individuals are affected, symptoms include medical problems, structural and functional brain alterations, cognitive and behavioural impairments, and psychiatric manifestations that are expressed at varying points during development (for a review, see [2]). One of the earliest studies of the behavioural phenotype pinpointed social problems as one of the most widespread difficulties occurring in the syndrome [3]. Several subsequent studies reported higher scores on parent ratings of social problems in children and adolescents with 22q11.2DS compared to typically developing individuals [4] [5] [6] [7].

Across development, it is likely that multiple factors contribute to the social impairments in 22q11.2DS. From a medical point of view, language and articulation deficits are one of the most common features of the syndrome [2]. Although the influence of velopharyngeal insufficiency (VPI) on social functioning has never been specifically investigated, parents and patients themselves frequently mention VPI as a barrier to engaging in social interactions. Speech difficulties can leave individuals feeling frustrated, unable to get their point across and to interact with others, especially with persons they do not know. Cognitive problems also contribute to impaired social relationships. In particular, executive function (EF) impairments are frequently encountered in patients with 22q11.2DS and tend to increase during adolescence [8] [9]. Indeed, social interactions are complex phenomena that require immediate adaptation to others and an ability to maintain focus on the current conversation while inhibiting irrelevant information [10]. EF deficits may thus contribute substantially to social impairments in general, and in 22q11.2DS patients in particular [8] [11].

Recent studies also have focused on the specific contribution of social cognitive impairments to the presence of social difficulties in 22q11.2DS [12]. It is well established that both the affective (i.e. emotion recognition and identification) and cognitive (i.e. theory of mind (ToM) and perspective taking) dimensions of social cognition are impaired in the syndrome [6] [13]-[19], but see [20]. Moreover, trouble recognizing faces and facial expressions have been linked to anomalies in visual form processing [18], as well as to the way patients visually scan faces [21] [22]. Individuals with 22q11.2DS were shown to look less at the eyes and more at the mouth when comparing faces [22] and when identifying facial emotions [21]. They also appear to be slower than typically developing individuals at recognizing dynamic emotional expressions [20] during the phase when an emotion becomes more obvious [23]. These deficits represent impediments to responding to others in a timely manner during interactions. However, despite the detection of these specific cognitive alterations, studies examining the relationship between social cognitive deficits and social functioning have not demonstrated a clear association between the two domains [6] [13] [14], making it difficult to isolate a putative cause of dysfunctional social behaviour.

Psychiatric disorders also can be an important obstacle to individuals' engagement in successful social interactions. Anxiety and internalizing disorders 
are particularly prevalent among young patients with 22q11.2DS [24] and were shown to negatively impact adaptive functioning [25] and social skills [6]. Later in life, during adolescence and adulthood, a large percentage of patients with 22q11.2DS experience negative symptoms of psychosis, including social withdrawal and a lack of emotional expressiveness [26] [27] [28] [29] [30]. Some of the social and communication deficits occurring in the syndrome can appear similar to those observed in individuals on the autism spectrum, especially when autism is evaluated using only the ADI-R interview (one part of a standardized autism evaluation). These impairments have supported the idea that a large portion of individuals with 22q11.2DS (20\% - 50\%) also may meet criteria for an autism spectrum disorder, given that it is still a behaviorally defined disorder [31] [32] [33]. However, subsequent work using gold-standard ASD evaluation procedures suggests that a smaller percentage of cases actually meet full criteria for autism [34].

\subsection{Tailoring Social Skills Training for Adolescents and Adults with 22q11.2DS}

Regardless of the causes underlying social impairment in 22q11.2DS, affected individuals are indisputably in need of social skills interventions. Social impairments compromise autonomy in 22q11.2DS [6], a social network or belonging to a social group can help individuals to overcome their social impairments and to become more independent. Recent reports show that it is possible to work effectively on social anxiety and social phobia in a group setting [35] and via online therapy [36]. Furthermore, a recent group intervention in 22q11.2DS demonstrated changes in social cognition [37]. This recent study, using a modified version of Cognitive Enhancement Therapy (CET) and done with a small sample of adolescents with 22q11.2DS, demonstrated that group interventions in the syndrome can be successful if they are tailored to participants' specific level of functioning and social difficulties. However, such interventions also must take into account parents' logistical concerns, such as geographic accessibility [37].

The SOSTA-FRA is a comprehensive social skills training program that was developed for patients with ASD [38]. In a multi-site randomized controlled trial, individuals with ASD who received the 12-week SOSTA-FRA intervention showed greater improvement on parent-rated social responsiveness compared to those who received treatment as usual [39]. Improvement was still evident three months after the end of the intervention. Many of the social skills encompassed by the SOSTA-FRA, such as looking people in the eye and making friends, also are pertinent for individuals with 22q11.2DS. To use the SOSTA-FRA with patients with 22q11.2DS, we made two changes: 1) We adapted the exercises to meet affected individuals' social needs; and 2) We used video conferencing to hold the group sessions (using the application Skype). Finding a way to hold the sessions remotely was particularly important for working with patients with $22 \mathrm{q} 11.2 \mathrm{DS}$ because of the rarity of the disorder. It allowed us to bridge the geo- 
graphic distance between affected individuals while providing social opportunities to those who live outside of urban areas and far from services.

In the present article, we describe the adapted version of the SOSTA-FRA, hereafter referred to as the SOSTA-22 digital version, and give results from a preliminary feasibility study performed on a sample of 22 adolescents and young adults with 22q11.2DS. We expected the program to be feasible and to elicit high levels of satisfaction by the parents. We also sought to establish sufficient pre-post effect sizes that may indicate improvement in social responsiveness, social withdrawal, and anxiety.

\section{Methods}

\subsection{Participants}

All participants volunteered for the study after receiving information from their local 22q11DS parent association. Patients considered for inclusion were between the ages of 11 and 30 with a confirmed genetic diagnosis of 22q11.2DS. Additionally, they needed easy residential access to an Internet connection, as well as the ability to participate in the sessions unaccompanied (stay sitting in front of the computer). Twenty-two participants aged between 11 and 26 years (mean age $=17.42$, sd $=4.71,15$ (68\%) females) were assigned according to age to one of the five groups. Participants were within two years of age to other members of the same group. A group was considered complete with four to six participants close in age (see first paragraph of the Results section). All participants and their parents gave informed consent to participate in the study using protocols approved by the Institutional Review Board.

\subsection{Pre- and Post-Assessment}

This initial feasibility study consisted of two evaluations, pre- and post-intervention, with 12 weekly sessions between the two evaluations (the intervention program is described in detail in section 2.4). For the evaluations, trained psychologists not involved in the clinical intervention administered a brief cognitive assessment using standardized instruments (Raven Progressive Matrices, and Peabody Picture Vocabulary Test) to the participants via Skype during the week preceding the intervention (T1) and again during the week following the end of the intervention (T2). Parents were sent a packet of questionnaires (including the satisfaction questionnaire, $\mathrm{CBCL} / \mathrm{ABCL}$ and SRS-II) and asked to complete them as close to the evaluation dates as possible.

\subsubsection{Satisfaction}

Parents rated feasibility and satisfaction with the program using a satisfaction questionnaire created for the study that focused on the content and the intervention setting. In the first part of the questionnaire, parents were asked about the usefulness of the different topics covered by the program ("not useful", "somewhat useful", or "very useful"), as well as changes in their offspring's social be- 
haviour and general well-being ("much worse", "a bit worse", "stable", "a bit improved", "much improved"). The themes were based on the projected objectives (see section 2.4). In the second part of the questionnaire, parents rated the technical and practical aspects of the program, especially regarding the use of the digital platform (items rated on a 5-point Likert scale ranging from "not at all" = 1 to "extremely" = 5). In the last part, parents reported their overall satisfaction with the program regarding the number of sessions and the duration of the sessions ("far too long", "a little too long", "adequate", "a little too short", and "far too short").

\subsubsection{Outcome Measures}

The effects on social responsiveness, social withdrawal, and anxiety were examined using parent-reported scales given pre- and post-intervention. The Social Responsiveness Scale II [SRS-II; [40]] estimates the following dimensions: social awareness, social cognition, social communication, social motivation, and restricted interests and repetitive behaviour. Given that social skills, as opposed to restricted interests and repetitive behaviours, were our main focus, only the T-scores from the first four domains were analysed. Higher scores on the SRS-II indicate increased social difficulties. Social withdrawal was assessed using the Withdrawn T-score from the Child Behavior Checklist [CBCL; [41]] or the Adult Behavior Checklist [ABCL; [42]], with higher scores indicating clinical levels of social withdrawal. Finally, elevated scores on the Anxious-Depressed $\mathrm{T}$-score from the $\mathrm{CBCL} / \mathrm{ABCL}$ indicated higher levels of anxiety and depression.

\subsection{Adaptation of the SOSTA-FRA to SOSTA-22 Digital Version}

The SOSTA-FRA is a structured program composed of 12 weekly sessions (approximately 3 months) that depends on progressive teaching [38], a strategy well-suited to stimulating lasting cognitive and behavioural changes in individuals with developmental delay [see also [43]]. In the SOSTA-FRA, the psychologist group leaders model positive social behaviour, and the content for each group session is outlined for the group leaders and focuses on a different building block of social behaviour. Participants practice skills, illustrated through examples, with their group and then generalize the skills through short homework assignments done at home or school.

Our research and clinical work with 22q11.2DS allowed us to narrow down a list of objectives for individuals with the syndrome. Some were the same as key aspects of the original SOSTA-FRA (i.e. paying attention to non-verbal cues), and others were specific to patients with 22q11.2DS (i.e. keeping a conversation going). We grouped the objectives conceptually and divided them into twelve progressive weekly sessions. Despite the digital platform, we sought to retain the structure of the SOSTA-FRA sessions by presenting information about a social skill and then practicing that skill through role-playing and group brainstorming. When an objective matched a topic from the SOSTA-FRA, we adapted the existing exercises to the online platform (Skype). When an objective was created 
for 22q11.2DS, we created pertinent exercises and designated a session in the 12 -week program to address the topic. The resulting progression became the curriculum for the SOSTA-22 digital version.

\subsection{Description of the SOSTA-22 Digital Version}

Before the first session, a virtual check-in was scheduled with each family (separate from the baseline evaluation) to verify their Internet connection and installation of Skype on their computer, and to familiarize them with video chatting (if necessary). The aim of this check-in was twofold: to avoid technical problems during the sessions due to slow Internet connections and to designate a quiet, private place at home where the participant would be able to concentrate during the sessions. We also requested that participants shut down all other applications on the computer to maximize performance of the Skype application and to minimize electronic distractions during the sessions. The sessions lasted 60 minutes on Skype, so it was important that each participant had a quiet workspace.

At the beginning of each session, one of the psychologists would place the video call to the group. It always took a few minutes for everyone to answer and settle in to the session. Once the participants answered, their videos appeared in the Skype window (Figure 1). In Skype, the two people who are speaking move to the top of the Skype window and the others stay at the bottom. The message area in Skype was especially useful for presenting concepts/information/examples, as well as for sharing ideas. There were times when participants felt more comfortable typing an idea in the message window than saying it. We also often used the "Share Screen" function of Skype to show videos or other stimuli to the group.

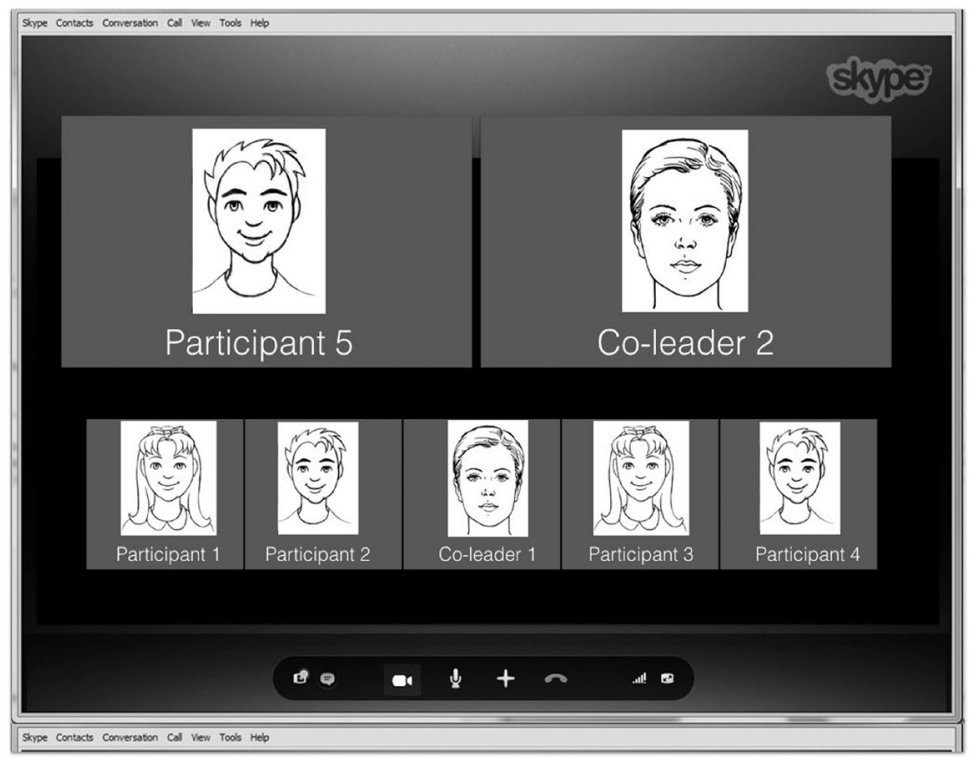

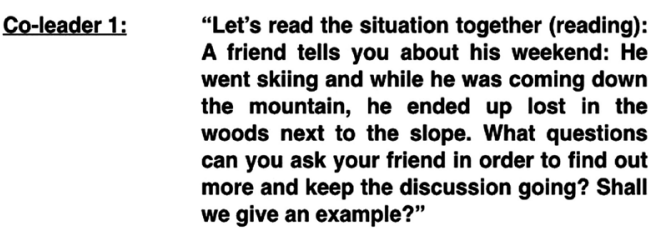

Co-leader 2:

"Yes, why don't I give an idea and then you give an idea, then we can go around the group. I think I would like to know more about how he left the slope and ended up in the woods. I would ask What an interesting story, how did you end up in the woods? What would you ask?"

Participant 5: “I would ask him, 'Did you get hurt?'”

Participant 1: "I would ask, “How did you find your way back?’”

Figure 1. Illustration of a group session via Skype with a written excerpt from Session 4 (topic: how to keep a conversation going). The two people who are speaking automatically move to the top of the Skype window during group chats. 
The SOSTA-22 digital version is divided into three main sections briefly described below:

Sessions 1 - 4: Good Communication (Unit objectives. Share and communicate thoughts and concerns with the group, learn to keep discussions going by asking open-ended questions, learn to perceive and use nonverbal communication).

As for the SOSTA-FRA, the first four sessions focused on a few concepts key to good communication, including establishing their personal objectives for program, reading nonverbal communication cues, approaching others and starting conversations, and keeping a conversation going. A written excerpt from a Session 4 exercise (topic: learning how to keep a conversation going) is provided in Figure 1.

Sessions 5 - 7: Learning about emotions (Unit objectives. Learn to name and discuss emotions, recognize emotions in ourselves and others, recognize and manage anger).

Sessions 5 - 7 focused on emotions: including recognizing and labelling emotions in others, recognizing emotions in ourselves and naming our emotions when talking to others, and recognizing and managing anger in ourselves.

Sessions 8 - 12: Social reciprocity and interaction (Unit objectives: Understand and recognize others intentions, practice initiating interactions, learn to give compliments, recognize limits in relationships and find strategies for managing these difficulties).

As in the SOSTA-FRA, the final sessions focused on interacting better with others by putting many of the learned skills to work. Specifically, in the SOSTA-22 digital version, we aimed to recognize our strengths and faults, understand others' perspectives, and problem solve during social interactions. The groups discuss questions such as "how to troubleshoot an interaction that has gotten off to a bad start" and work on unfinished exercises from previous sessions or continues work on topics that were especially challenging (i.e. How to present oneself in a particular situation; or how to strike a formal vs. informal tone.). As the group goes through the 12-week program, participants gradually become accustomed to sharing personal experiences with each other and tend to bring difficult situations directly to the group by the third month.

For the adolescent groups, the group leaders organized a session with the parents after each month of the program to share the material covered and observations from the sessions. At the end of the program, a final session was conducted with participants and their parents to discuss what was accomplished during the group and to make a plan for keeping in touch.

\subsection{Statistical Methods}

Descriptive data were reported from the satisfaction questionnaire to investigate parents' opinions on program feasibility, the practical aspects of the program (e.g. length of the sessions) and their perspectives on their offspring's improvement in several social competency domains. Significant changes between pre- 
and post-assessment scores were analysed using repeated-measures ANOVA for Raven's Matrices, PPVT, SRS-II, and the CBCL/ABCL questionnaires. Effect sizes were interpreted using Cohen's guidelines for the partial-eta squared values [44]: small effect $=0.10$, medium effect $=0.25$, and large effect $=0.40$.

\section{Results}

\subsection{Participants, Dropout Rate and Adverse Events}

Of the 22 participants, one participant had to decline participation after being accepted in the study because she was not available during the evening hours when the group sessions took place. The 21 remaining participants were divided into three groups of adolescents (ages 11 - 16) and two groups of adults (ages 19 - 26) according to age, with four to five participants per group. Participants had receptive vocabulary abilities in the low-average range according to the Peabody Picture Vocabulary Test $(93.61 \pm 17.52)$, and low scores on the Raven's Progressive Matrices $(52.13 \pm 17.52)$ (Table S1). The parents of participants had an average of $14.97 \pm 2.34$ years of education.

The dropout rate from the study was $14 \%(\mathrm{~N}=3)$. These participants were not evaluated at follow-up for the following reasons: two patients and their families were going through a period of acute stress, which prevented them from continuing with the sessions; a third participant completed the intervention but attended less than $75 \%$ of the sessions (5/12 sessions (42\%)). Results are reported only for participants who completed both evaluations and the program $(\mathrm{N}=18)$. Out of those 18, 12 patients (66.7\%) participated in all 12 sessions, three (16.7\%) participated in 11 sessions, and three (16.7\%) participated in 10 sessions. Three participants dealt with medical problems (complications due to a heart malformation, infectious diseases, or ambulatory surgical interventions) during the study, all of which were unrelated to the clinical intervention.

Nine (42\%) participants were taking psychiatric medication at the time of the first assessment, which is commensurate with other studies of patients with 22q11.2DS [45]. Two were being treated with antidepressants, two with methylphenidate, three with a combination of antipsychotics and antidepressants, one with a combination of antipsychotics and methylphenidate, and one with a combination of antipsychotics, antidepressants, and methylphenidate. No medication changes were reported during the course of the clinical trial. Nine (42\%) participants were receiving regular psychosocial interventions by a speech therapist $(\mathrm{N}=3)$, a psychologist/psychiatrist $(\mathrm{N}=2)$, or both $(\mathrm{N}=4)$. One participant who was not receiving outside therapies at the pre-intervention assessment started regular appointments (one session/month) with a psychiatrist during the 12 -week intervention. Neither participants, nor their parents, reported adverse events related to the intervention.

\subsection{Parent Satisfaction}

Parents reported a high degree of satisfaction with the practical aspects of the 
program and a minimal need to assist their offspring during the sessions (see Table 1). Session length (60 minutes) was rated as adequate by $14(77.8 \%)$ parents. However, only six (33.3\%) rated the duration of the entire program (12 sessions) as adequate. The remaining parents reported that the intervention was either a little too short $(\mathrm{N}=9,50 \%)$ or far too short $(\mathrm{N}=3,16.7 \%)$.

A majority of parents reported that the themes covered by the program were "somewhat useful" or "very useful" (see Table 2). Parents also had the opportunity to comment on whether an important theme was lacking in the program. The following suggestions were proposed: dating/sexuality $(\mathrm{n}=1)$, explaining our handicap to others $(n=1)$, developing critical thinking, being able to refuse or respond appropriately to a sales pitch $(\mathrm{n}=1)$, and staying focused during conversations (without going off on a tangent) $(n=1)$.

Parents also rated the effect of the intervention on social difficulties and general well-being (see Table 3). None of the parents reported signs of worsening in any of the domains. Four domains were rated as improved by the majority of the parents: emotional awareness, general well-being/mood, reciprocal conversations, and recognizing/naming one's emotions.

\subsection{Pre- and Post-Intervention Results}

At baseline, the group's mean SRS-II total T-score (moderate clinical range, T-score $>66$ ) and the Withdrawn and Anxious-Depressed T-scores from the $\mathrm{CBCL} / \mathrm{ABCL}$ ( $\mathrm{T}$-score $>63$ ) were in the clinical range (see Table 4).

Table 1. Parent ratings of program logistics. Items were rated on a 5-point Likert scale (1 $=$ not at all to $5=$ extremely).

\begin{tabular}{cc}
\hline Item & Mean (sd) \\
\hline Convenience of the digital setting for parents & $4.56(0.62)$ \\
Participant at ease with the digital platform & $4.33(0.97)$ \\
Need for parent assistance during sessions & $2.4(0.94)$ \\
\hline
\end{tabular}

Table 2. Usefulness of the main themes covered by the program.

\begin{tabular}{cccc}
\hline Theme & Not useful & Somewhat useful & Very useful \\
\hline Using eye contact & $5(27.8 \%)$ & $3(16.7 \%)$ & $10(55.6 \%)$ \\
Increasing awareness of emotions & $2(11.1 \%)$ & $4(22.2 \%)$ & $12(66.7 \%)$ \\
Understanding non-verbal communication & $3(16.7 \%)$ & $4(22.2 \%)$ & $11(61.1 \%)$ \\
Skills to approach others more comfortably & $1(5.6 \%)$ & $4(22.2 \%)$ & $13(72.2 \%)$ \\
Increasing enjoyment from time with others & $1(5.6 \%)$ & $4(22.2 \%)$ & $13(72.2 \%)$ \\
Developing social communication skills & $0(0 \%)$ & $7(38.9 \%)$ & $11(61.1 \%)$ \\
Social problem solving & $2(11.1 \%)$ & $8(44.4 \%)$ & $8(44.4 \%)$ \\
Dealing with teasing or bullying & $4(22.2 \%)$ & $7(38.9 \%)$ & $7(38.9 \%)$ \\
Coping with negative emotions & $1(5.6 \%)$ & $7(38.9 \%)$ & $10(55.6 \%)$ \\
\hline
\end{tabular}


Table 3. Parent ratings of their adolescent's improvement following the clinical intervention.

\begin{tabular}{cccc}
\hline Domain & Worsened $^{\mathrm{a}}$ & Stable & Improved $^{\mathrm{b}}$ \\
\hline Self-esteem & $0(0 \%)$ & $9(50 \%)$ & $9(50 \%)$ \\
Openness towards others & $0(0 \%)$ & $10(55.6 \%)$ & $8(44.4 \%)$ \\
Awareness of emotions & $0(0 \%)$ & $6(33.3 \%)$ & $12(66.7 \%)$ \\
General well-being/mood & $0(0 \%)$ & $8(44.4 \%)$ & $10(55.6 \%)$ \\
Reciprocity during conversations & $0(0 \%)$ & $7(38.9 \%)$ & $11(61.1 \%)$ \\
Recognizing and naming one's emotions & $0(0 \%)$ & $6(33.3 \%)$ & $12(66.7 \%)$ \\
Coping with emotions & $0(0 \%)$ & $13(72.2 \%)$ & $5(27.8 \%)$ \\
Recognizing and naming others' emotions & $0(0 \%)$ & $13(72.2 \%)$ & $5(27.8 \%)$ \\
\hline
\end{tabular}

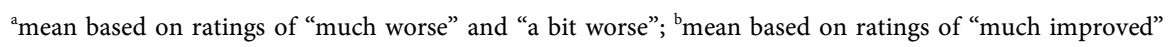
and "a bit improved".

Table 4. Cognitive and clinical results from before and after the intervention.

\begin{tabular}{|c|c|c|c|c|}
\hline & $\begin{array}{c}\text { Pre-assessment } \\
\text { (T1) }\end{array}$ & $\begin{array}{c}\text { Post-assessment } \\
\text { (T2) }\end{array}$ & Statistical test & $\begin{array}{l}\text { Partial Eta } \\
\text { Squared }\end{array}$ \\
\hline \multicolumn{5}{|l|}{ Social responsiveness } \\
\hline SRS-II total TS & $67.22(14.27)$ & $64.39(14.03)$ & $\begin{array}{c}\mathrm{F}(1,17)=4.738 \\
p=0.044\end{array}$ & 0.218 \\
\hline SRS-II social awareness TS & $66.17(11.24)$ & $60.22(10.38)$ & $\begin{array}{c}\mathrm{F}(1,17)=13.044 \\
p=0.002\end{array}$ & 0.434 \\
\hline SRS-II social cognition TS & $66.17(13.84)$ & $65.06(12.95)$ & $\begin{array}{c}\mathrm{F}(1,17)=0.652 \\
\quad p=0.431\end{array}$ & 0.037 \\
\hline $\begin{array}{c}\text { SRS-II social communication } \\
\text { TS }\end{array}$ & $62.72(17.55)$ & $62.83(13.93)$ & $\begin{array}{c}\mathrm{F}(1,17)=0.002 \\
\quad p=0.964\end{array}$ & $<0.001$ \\
\hline SRS-II social motivation TS & $63.44(14.18)$ & $60.06(12.17)$ & $\begin{array}{c}\mathrm{F}(1,17)=4.684 \\
p=0.045\end{array}$ & 0.216 \\
\hline \multicolumn{5}{|l|}{ Social withdrawal } \\
\hline CBCL/ABCL withdrawn TS & $64.89(8.99)$ & $62.33(10.40)$ & $\begin{array}{c}\mathrm{F}(1,17)=2.656 \\
\quad p=0.122\end{array}$ & 0.135 \\
\hline \multicolumn{5}{|l|}{ Anxiety } \\
\hline $\begin{array}{c}\mathrm{CBCL} / \mathrm{ABCL} \\
\text { anxious-depressed TS }\end{array}$ & $64.11(10.59)$ & $62.39(12.12)$ & $\begin{array}{c}\mathrm{F}(1,17)=1.290 \\
p=0.272\end{array}$ & 0.071 \\
\hline
\end{tabular}

Repeated-measures ANOVA revealed significant changes in SRS-II scores between the two evaluations. Specifically, the total T-score, social awareness, and social motivation subscales decreased at $\mathrm{T} 2$ compared to T1, indicating improved social responsiveness (Table 4). The effect sizes for the Total and Social Motivation T-scores are considered small to medium $(\leq 0.25)$ and the effect size for the Social Awareness dimension is considered large $(\geq 0.40)$. There was no change in the remaining two SRS-II dimensions between T1 and T2, or in the CBCL/ABCL Withdrawn or Anxious-Depressed subscales. Individual changes 
between $\mathrm{T} 2$ and $\mathrm{T} 1$ are given in Table 4.

\section{Discussion}

This study suggests that using online video-conferencing to bring social skills training groups to geographically dispersed patients is feasible. Moreover, results from the satisfaction survey indicate that the SOSTA-22 digital version curriculum addresses topics that are well-suited to the needs of adolescents and young adults with 22q11.2DS. Parents also noted social skills improvement in their offspring following the intervention. They rated their adolescents or young adults as especially improved in the domains of emotional awareness, general well-being, reciprocity during conversations and naming their emotions. Commensurate with these observations, we observed improvement on the Total Score, Social Awareness and Social Motivation domains of the SRS-II, a standardized measure of social difficulties. Participants also frequently expressed enjoyment of the group experience and sadness to see it end.

\subsection{Parent Satisfaction and Feasibility of the SOSTA-22 Digital Version}

One previous study has used a group intervention to improve social skills in 22q11.2DS [37]. There are fundamental differences between the program used in Shashi et al's study and the SOSTA-22 digital version, including the use of live groups (as opposed to online), a cognitive enhancement therapy approach and the inclusion of adolescents exclusively. However, there are also important similarities between their study and ours (group size, common topics covered, support for both, adolescents and parents, rates of medications among participants and overall parent satisfaction) that suggest that group interventions are both feasible and generally well-received among families affected by the syndrome. Similar to the parents' reactions to the previous study [37], participants' parents reported feeling very satisfied with their overall group experience during the study.

In addition, we collected detailed data and suggestions from both parents and participants to assess satisfaction with the unique online format. Parents found it easy to organize their child's participation in the groups and reported that the participants were at ease with the platform. When families had less experience using digital communication platforms, the simplicity of the Skype interface helped them to get comfortable. Parents were pleased that they could participate from the comfort of their own homes, rather than transporting their adolescent to yet another appointment, given that youngsters with developmental disorders often have multiple therapy/medical appointments during the week. The relatively minimal effort required by participants and their families likely contributed to the excellent attendance of participants at the sessions and their overall enthusiasm. High levels of parent satisfaction also have been reported for other types of digital interventions, such as tablet applications targeting cognitive 
abilities. One recent such study in ASD estimated ease of use for participating families at $100 \%$ despite a lack of improvement in social communication skills [46].

Similar to the previous group study in 22q11.2DS [37], we also experienced low attrition rates. Only three participants had to be excluded from T2 analyses, all of which were for reasons independent of the content or setting. Most of our participants attended all of the sessions, and all included participants participated in at least 10 out of 12 sessions, which is higher than rates from the other group study in 22q11.2DS [37]. This difference is most certainly due, at least in part, to the fact that our intervention was comprised of less than half the number of sessions (12 vs. 26 sessions).

Responses and behaviour also indicated high adherence to the online format. Participants were motivated to log-on for the sessions and often expressed that it was relaxing to log-on from home and "see" a group of friends. All five groups spontaneously exchanged contact information at the end of the program to keep in touch. A previous report of a cognitive (vs. social) digital program administered to youths affected by the syndrome, indicated that parents had a more difficult time motivating participants to stick with the program exercises [47]. One possible explanation for this difference may be that by adolescence and young adulthood, affected individuals are more aware of their difficulties, and thus more motivated to complete a targeted intervention. Though another possibility is that participants were especially motivated for the group dynamic offered in a social intervention (and missing in an individually-based cognitive intervention). Future studies will have to keep close tabs on participants' overall motivation to better understand how to best remediate different impairments.

Monthly discussions about the program with participants' parents allowed them to assist their adolescents to generalize their knowledge and give the coleaders important feedback during the program. Parents found all the main themes of the program to be "somewhat" to "very useful". Interestingly, many of the highest-rated themes matched the objectives that participants identified for themselves during the first session of the program, suggesting some initial self-awareness. Examples of some of the convergent themes that were highly rated by the parents at post-remediation and oft-mentioned in the participants' goals for themselves include, respectively: skills for approaching others (learn how to initiate interactions), increased enjoyment from spending time with others (deepen relationships with others), understanding nonverbal communication/develop social communication skills (understanding indirect communication), and using eye contact (look others in the eye).

Parents also suggested additional themes that were more specific than some of the general social skills taught in the program. For example, they would have liked to see topics, such as dating situations, responding to confrontation and refusing a sales pitch addressed more specifically. When we adapted the SOSTAFRA to the syndrome, we substituted many of the role-play scenarios to match 
real-life recurrent situations that are difficult for individuals with 22q11.2DS. However, the parents' suggestions would argue for a longer intervention, allowing for the more extensive application of the skills taught in the program to specific situations that tend to be difficult for individuals with 22q11.2DS. Given that 12 out of 18 parents judged the program as being too short or much too short, lengthening the program would allow more time for each concept, revisiting topics that are initially difficult for participants. Interestingly, the parents included in the previous group study also expressed the need for a longer intervention, despite the fact that it lasted more than twice as long as the current study [37]. This may be an indication of the level of concern that parents feel about their offspring's social skills.

The domains that parents judged to be improved at the post-intervention evaluation were mostly related to the patients' understanding of themselves, as opposed to their understanding of others. These included "general well-being", "being aware and naming their own emotions" and being "more reciprocal in discussions". In addition to the themes discussed, it was very rewarding for patients to meet other participants with the same syndrome, making it difficult to separate the putative benefit of having scheduled social time from that of working on material tailored to their specific needs.

\subsection{First Effects of the SOSTA-22 Digital Version}

Our pre-post results indicate a decline in SRS-II scores immediately after the intervention. Changes were reported on two dimensions; a large effect size was observed for the changes in social awareness (i.e. ability to pick up on social cues) and a small effect size for social motivation (i.e. ability to engage in social interpersonal behaviours). These changes are encouraging in that they indicate the potential for improving social awareness especially in 22q11.2DS and are commensurate with the enthusiasm for the intervention expressed by participants.

Our pre-post effects are similar to those from a study using the SOSTA-FRA program with a large sample of children and adolescents with ASD [39], the authors also observed a decrease in SRS Total Score (as well as on all the SRS dimensions) in ASD patients who completed the SOSTA-FRA compared to the control group (treatment as usual) at the end of intervention and after a 3-month follow-up. Although the two studies differ in important ways in terms of design, age of participants (ours were slightly older), cognitive ability (we did not exclude participants based on IQ), and number of participants included, the similarities between the results suggest that the original SOSTA-FRA and the SOSTA-22 digital version share common properties that may be effective at improving social responsiveness in both patients with high-functioning ASD and 22q11.2DS.

The implementation of another curriculum showed different results. Shashi et al. found no effect on social skills and social functioning from Cognitive En- 
hancement Therapy (CET) program in a sample of 13 adolescents with 22q11.2DS [37]. However, the program used was created for adults with psychosis and then adapted for use with young patients with 22q11.2DS. Its aim was to target perspective-taking, and the identification of non-verbal social cues. Although both programs have overlapping aims, the modified CET may target more sophisticated social skills. Future studies based on broader samples may consider analysing potential moderators (e.g. age, IQ level) of treatment outcome and using effect sizes to indicate improvement to help identify optimal participant characteristics for each program.

Recent work indicates that social and communication difficulties may increase the risk for developing social anxiety disorder [48], which may well be the case in 22q11.2DS. However, despite evidence for a relationship between social competency and emotional problems in 22q11.2DS [6], the present study did not provide evidence for an effect of the SOSTA-22 digital version on symptoms of anxiety or social withdrawal. This is commensurate with the results from a study based on the SOSTA-FRA program [39], despite the fact that, unlike our patients, the SOSTA-FRA participants did not show clinical impairment in the anxious-depressed domain of the CBCL at baseline. One explanation for this is that anxiety and withdrawal may not be directly related to the abilities targeted by the program and may therefore be influenced only indirectly in ways that are not noticeable when evaluating a small sample immediately before and after the program. For example, the anxious-depressed dimension of the CBCL/ABCL assesses general affective manifestations (e.g. "cries a lot", "tends to worry") rather than indications of social anxiety. In the future, it would be interesting to include a more detailed assessment of specific anxiety symptoms and sub-types of anxiety to better understand the relationship between social skills interventions and symptoms of anxiety. It also should be noted that our sample size was underpowered to detect small effects on affective difficulties.

\subsection{Limitations and Conclusions}

Our results are clearly preliminary and limited by our small sample, lack of randomization and a control group and the absence of additional data points post-intervention. Participants were evaluated immediately preceding the start of the program and immediately following the program. Furthermore, the results of this study make it difficult to isolate the components of the SOSTA-22 digital version that directly contribute to the observed changes in social responsiveness. It may be that meeting other individuals with 22q11.2DS and sharing personal experiences together is a beneficial intervention in itself, independent of the contents of the SOSTA-22 digital version. Moreover, our results may be threatened by a self-selection bias, the adolescents and young adults who volunteer to participate in a group may be fundamentally more motivated, making it easier to remediate their social skills. For these reasons, future studies should include an active control condition (e.g. unstructured group sessions providing 
togetherness) to better understand the specific impact of the program. Another limitation relates to our choice of outcome measures and has been detailed in Freitag et al. [39]. Our measures required a parent report, which can differ significantly from other perspectives [49]. Future studies may want to consider including standardized tests of social functioning that do not rely on reports from participants or their parents.

\section{Conclusion}

In conclusion, the present study demonstrates the feasibility of social skills training for adolescents and young adults with 22q11.2DS via online video-conferencing and provides preliminary evidence for improving social responsiveness through a group intervention. While nothing can take the place of true togetherness, sharing a room and time with others, the SOSTA-22 digital version represents the type of program that can provide an excellent option for youngsters with rare and isolating conditions in difficult-to-reach localities.

\section{Acknowledgements}

We would like to thank the adolescents and adults who participated in the study, as well as their parents. Heartfelt thanks go to Elisabeth Eliez for many hours spent translating the SOSTA-net manual. We further extend our appreciation to Matthieu Mansion, Isaline Mottet, Lucie Chambeyron, Aude Burkel, and Sarah Menghetti for their work with the participating families. This study was funded by the Swiss National Science Foundation (grant number \#324730_144260 to Stephan Eliez). M. Schneider also was supported by a personal fellowship from the Swiss National Science Foundation (grant number \#162006).

\section{References}

[1] Botto, L.D., May, K., Fernhoff, P.M., Correa, A., Coleman, K., Rasmussen, S.A., Merritt, R.K., O’Leary, L.A., Wong, L.Y., Elixson, E.M., Mahle, W.T. and Campbell, R.M. (2003) A Population-Based Study of the 22q11.2 Deletion: Phenotype, Incidence, and Contribution to Major Birth Defects in the Population. Pediatrics, 112, 101-107. https://doi.org/10.1542/peds.112.1.101

[2] Shprintzen, R.J. (2008) Velo-Cardio-Facial Syndrome: 30 Years of Study. Developmental Disabilities Research Reviews, 14, 3-10. https://doi.org/10.1002/ddrr.2

[3] Swillen, A., Devriendt, K., Legius, E., Eyskens, B., Dumoulin, M., Gewillig, M. and Fryns, J.P. (1997) Intelligence and Psychosocial Adjustment in Velocardiofacial Syndrome: A Study of 37 Children and Adolescents with VCFS. Journal of Medical Genetics, 34, 453-458. https://doi.org/10.1136/jmg.34.6.453

[4] Bearden, C.E., Jawad, A.F., Lynch, D.R., Monterossso, J.R., Sokol, S., McDonald-McGinn, D.M., Saitta, S.C., Harris, S.E., Moss, E., Wang, P.P., Zackai, E., Emanuel, B.S. and Simon, T.J. (2005) Effects of COMT Genotype on Behavioral Symptomatology in the 22q11.2 Deletion Syndrome. Child Neuropsychology, 11, 109-117. https://doi.org/10.1080/09297040590911239

[5] Kiley-Brabeck, K. and Sobin, C. (2006) Social Skills and Executive Function Deficits in Children with the 22q11 Deletion Syndrome. Applied Neuropsychology, 13, 
258-268. https://doi.org/10.1207/s15324826an1304_7

[6] Shashi, V., Veerapandiyan, A., Schoch, K., Kwapil, T., Keshavan, M., Ip, E. and Hooper, S. (2012) Social Skills and Associated Psychopathology in Children with Chromosome 22q11.2 Deletion Syndrome: Implications for Interventions. Journal of Intellectual Disability Research, 56, 865-878. https://doi.org/10.1111/j.1365-2788.2011.01477.x

[7] Woodin, M., Wang, P.P., Aleman, D., McDonald-McGinn, D., Zackai, E. and Moss, E. (2001) Neuropsychological Profile of Children and Adolescents with the 22q11.2 Microdeletion. Genetics in Medicine, 3, 34-39. https://doi.org/10.1097/00125817-200101000-00008

[8] Maeder, J., Schneider, M., Bostelmann, M., Debbane, M., Glaser, B., Menghetti, S., Schaer, M. and Eliez, S. (2016) Developmental Trajectories of Executive Functions in 22q11.2 Deletion Syndrome. Journal of Neurodevelopmental Disorders, 8, 10. https://doi.org/10.1186/s11689-016-9141-1

[9] Shapiro, H.M., Tassone, F., Choudhary, N.S. and Simon, T.J. (2014) The Development of Cognitive Control in Children with Chromosome 22q11.2 Deletion Syndrome. Frontiers in Psychology, 5, 566. https://doi.org/10.3389/fpsyg.2014.00566

[10] Ybarra, O. and Winkielman, P. (2012) On-Line Social Interactions and Executive Functions. Frontiers in Human Neurosciences, 6, 75. https://doi.org/10.3389/fnhum.2012.00075

[11] Schneider, M., Eliez, S., Birr, J., Menghetti, S., Debbane, M. and Van der Linden, M. (2016) Multitasking Abilities in Adolescents with 22q11.2 Deletion Syndrome: Results from an Experimental Ecological Paradigm. American Journal on Intellectual and Developmental Disabilities, 121, 151-164. https://doi.org/10.1352/1944-7558-121.2.151

[12] Norkett, E.M., Lincoln, S.H., Gonzalez-Heydrich, J. and D’Angelo, E.J. (2017) Social Cognitive Impairment in 22q11 Deletion Syndrome: A Review. Psychiatry Research, 253, 99-106. https://doi.org/10.1016/j.psychres.2017.01.103

[13] Campbell, L.E., McCabe, K.L., Melville, J.L., Strutt, P.A. and Schall, U. (2015) Social Cognition Dysfunction in Adolescents with 22q11.2 Deletion Syndrome (Velo-Cardio-Facial Syndrome): Relationship with Executive Functioning and Social Competence/Functioning. Journal of Intellectual Disability Research, 59, 845-859. https://doi.org/10.1111/jir.12183

[14] Campbell, L.E., Stevens, A.F., McCabe, K., Cruickshank, L., Morris, R.G., Murphy, D.G. and Murphy, K.C. (2011) Is Theory of Mind Related to Social Dysfunction and Emotional Problems in 22q11.2 Deletion Syndrome (Velo-Cardio-Facial Syndrome)? Journal of Neurodevelopmental Disorders, 3, 152-161. https://doi.org/10.1007/s11689-011-9082-7

[15] Gur, R.E., Yi, J.J., McDonald-McGinn, D.M., Tang, S.X., Calkins, M.E., Whinna, D., Souders, M.C., Savitt, A., Zackai, E.H., Moberg, P.J., Emanuel, B.S. and Gur, R.C. (2014) Neurocognitive Development in 22q11.2 Deletion Syndrome: Comparison with Youth Having Developmental Delay and Medical Comorbidities. Molecular Psychiatry, 19, 1205-1211. https://doi.org/10.1038/mp.2013.189

[16] Ho, J.S., Radoeva, P.D., Jalbrzikowski, M., Chow, C., Hopkins, J., Tran, W.C., Mehta, A., Enrique, N., Gilbert, C., Antshel, K.M., Fremont, W., Kates, W.R. and Bearden, C.E. (2012) Deficits in Mental State Attributions in Individuals with 22q11.2 Deletion Syndrome (Velo-Cardio-Facial Syndrome). Autism Research, 5, 407-418. https://doi.org/10.1002/aur.1252

[17] Jalbrzikowski, M., Carter, C., Senturk, D., Chow, C., Hopkins, J.M., Green, M.F., 
Galvan, A., Cannon, T.D. and Bearden, C.E. (2012) Social Cognition in 22q11.2 Microdeletion Syndrome: Relevance to Psychosis? Schizophrenia Research, 142, 99-107. https://doi.org/10.1016/j.schres.2012.10.007

[18] McCabe, K.L., Melville, J.L., Rich, D., Strutt, P.A., Cooper, G., Loughland, C.M., Schall, U. and Campbell, L.E. (2013) Divergent Patterns of Social Cognition Performance in Autism and 22q11.2 Deletion Syndrome (22q11DS). Journal of Autism and Developmental Disorders, 43, 1926-1934.

https://doi.org/10.1007/s10803-012-1742-2

[19] McCabe, K.L., Marlin, S., Cooper, G., Morris, R., Schall, U., Murphy, D.G., Murphy, K.C. and Campbell, L.E. (2016) Visual Perception and Processing in Children with 22q11.2 Deletion Syndrome: Associations with Social Cognition Measures of Face Identity and Emotion Recognition. Journal of Neurodevelopmental Disorders, 8, 30. https://doi.org/10.1186/s11689-016-9164-7

[20] Franchini, M., Schaer, M., Glaser, B., Kott-Radecka, M., Debanne, M., Schneider, M., Menghetti, S., Sander, D. and Eliez, S. (2016) Visual Processing of Emotional Dynamic Faces in 22q11.2 Deletion Syndrome. Journal of Intellectual Disability Research, 60, 308-321. https://doi.org/10.1111/jir.12250

[21] Campbell, L., McCabe, K., Leadbeater, K., Schall, U., Loughland, C. and Rich, D. (2010) Visual Scanning of Faces in 22q11.2 Deletion Syndrome: Attention to the Mouth or the Eyes? Psychiatry Research, 177, 211-215. https://doi.org/10.1016/j.psychres.2009.06.007

[22] Glaser, B., Debbane, M., Ottet, M.C., Vuilleumier, P., Zesiger, P., Antonarakis, S.E. and Eliez, S. (2010) Eye Gaze during Face Processing in Children and Adolescents with 22q11.2 Deletion Syndrome. Journal of the American Academy of Child and Adolescent Psychiatry, 49, 665-674.

[23] Leleu, A., Saucourt, G., Rigard, C., Chesnoy, G., Baudouin, J.Y., Rossi, M., Edery, P., Franck, N. and Demily, C. (2016) Facial Emotion Perception by Intensity in Children and Adolescents with 22q11.2 Deletion Syndrome. European Child and Adolescent Psychiatry, 25, 297-310. https://doi.org/10.1007/s00787-015-0741-1

[24] Schneider, M., Debbane, M., Bassett, A.S., Chow, E.W., Fung, W.L., van den Bree, M., Owen, M., Murphy, K.C., Niarchou, M., Kates, W.R., Antshel, K.M., Fremont, W., McDonald-McGinn, D.M., Gur, R.E., Zackai, E.H., Vorstman, J., Duijff, S.N., Klaassen, P.W., Swillen, A., Gothelf, D., Green, T., Weizman, A., Van Amelsvoort, T., Evers, L., Boot, E., Shashi, V., Hooper, S.R., Bearden, C.E., Jalbrzikowski, M., Armando, M., Vicari, S., Murphy, D.G., Ousley, O., Campbell, L.E., Simon, T.J. and Eliez, S. (2014) Psychiatric Disorders from Childhood to Adulthood in 22q11.2 Deletion Syndrome: Results from the International Consortium on Brain and Behavior in 22q11.2 Deletion Syndrome. American Journal of Psychiatry, 171, 627-639. https://doi.org/10.1176/appi.ajp.2013.13070864

[25] Angkustsiri, K., Leckliter, I., Tartaglia, N., Beaton, E.A., Enriquez, J. and Simon, T.J. (2012) An Examination of the Relationship of Anxiety and Intelligence to Adaptive Functioning in Children with Chromosome 22q11.2 Deletion Syndrome. Journal of Developmental \& Behavioral Pediatrics, 33, 713-720. https://doi.org/10.1097/DBP.0b013e318272dd24

[26] Armando, M., Girardi, P., Vicari, S., Menghini, D., Digilio, M.C., Pontillo, M., Saba R., Mazzone, L., Lin, A., Klier, C.M., Schafer, M.R. and Amminger, G.P. (2012) Adolescents at Ultra-High Risk for Psychosis with and without 22q11 Deletion Syndrome: A Comparison of Prodromal Psychotic Symptoms and General Functioning. Schizophrenia Research, 139, 151-156.

https://doi.org/10.1016/j.schres.2012.04.020 
[27] Schneider, M., Van der Linden, M., Glaser, B., Rizzi, E., Dahoun, S.P., Hinard, C., Bartoloni, L., Antonarakis, S.E., Debbane, M. and Eliez, S. (2012) Preliminary Structure and Predictive Value of Attenuated Negative Symptoms in 22q11.2 Deletion Syndrome. Psychiatry Research, 196, 277-284. https://doi.org/10.1016/j.psychres.2011.08.017

[28] Schneider, M., Van der Linden, M., Menghetti, S., Glaser, B., Debbane, M. and Eliez, S. (2014) Predominant Negative Symptoms in 22q11.2 Deletion Syndrome and Their Associations with Cognitive Functioning and Functional Outcome. Journal of Psychiatric Research, 48, 86-93. https://doi.org/10.1016/j.jpsychires.2013.10.010

[29] Stoddard, J., Niendam, T., Hendren, R., Carter, C. and Simon, T.J. (2010) Attenuated Positive Symptoms of Psychosis in Adolescents with Chromosome 22q11.2 Deletion Syndrome. Schizophrenia Research, 118, 118-121.

https://doi.org/10.1016/j.schres.2009.12.011

[30] Vangkilde, A., Jepsen, J.R., Schmock, H., Olesen, C., Arnarsdottir, S., Baare, W.F., Plessen, K.J., Didriksen, M., Siebner, H.R., Werge, T. and Olsen, L. (2016) Associations between Social Cognition, Skills, and Function and Subclinical Negative and Positive Symptoms in 22q11.2 Deletion Syndrome. Journal of Neurodevelopmental Disorders, 8, 42. https://doi.org/10.1186/s11689-016-9175-4

[31] Fine, S.E., Weissman, A., Gerdes, M., Pinto-Martin, J., Zackai, E.H., McDonald-McGinn, D.M. and Emanuel, B.S. (2005) Autism Spectrum Disorders and Symptoms in Children with Molecularly Confirmed 22q11.2 Deletion Syndrome. Journal of Autism and Developmental Disorders, 35, 461-470. https://doi.org/10.1007/s10803-005-5036-9

[32] Niklasson, L., Rasmussen, P., Oskarsdottir, S. and Gillberg, C. (2009) Autism, ADHD, Mental Retardation and Behavior Problems in 100 Individuals with 22q11 Deletion Syndrome. Research in Developmental Disabilities, 30, 763-773. https://doi.org/10.1016/j.ridd.2008.10.007

[33] Vorstman, J.A., Morcus, M.E., Duijff, S.N., Klaassen, P.W., Heineman-de Boer, J.A., Beemer, F.A., Swaab, H., Kahn, R.S. and van Engeland, H. (2006) The 22q11.2 Deletion in Children: High Rate of Autistic Disorders and Early Onset of Psychotic Symptoms. Journal of the American Academy of Child and Adolescent Psychiatry, 45, 1104-1113. https://doi.org/10.1097/01.chi.0000228131.56956.c1

[34] Angkustsiri, K., Goodlin-Jones, B., Deprey, L., Brahmbhatt, K., Harris, S. and Simon, T.J. (2014) Social Impairments in Chromosome 22q11.2 Deletion Syndrome (22q11.2DS): Autism Spectrum Disorder or a Different Endophenotype? Journal of Autism and Developmental Disorders, 44, 739-746.

https://doi.org/10.1007/s10803-013-1920-x

[35] Wersebe, H., Sijbrandij, M. and Cuijpers, P. (2013) Psychological Group-Treatments of Social Anxiety Disorder: A Meta-Analysis. PLOS ONE, 8, e79034. https://doi.org/10.1371/journal.pone.0079034

[36] Andrews, G., Davies, M. and Titov, N. (2011) Effectiveness Randomized Controlled Trial of Face to Face versus Internet Cognitive Behaviour Therapy for Social Phobia. Australian \& New Zealand Journal of Psychiatry, 45, 337-340. https://doi.org/10.3109/00048674.2010.538840

[37] Shashi, V., Harrell, W., Eack, S., Sanders, C., McConkie-Rosell, A., Keshavan, M.S., Bonner, M.J., Schoch, K. and Hooper, S.R. (2015) Social Cognitive Training in Adolescents with Chromosome 22q11.2 Deletion Syndrome: Feasibility and Preliminary Effects of the Intervention. Journal of Intellectual Disability Research, 59, 902-913. https://doi.org/10.1111/jir.12192 
[38] Freitag, C.M., Cholemkery, H., Elsuni, L., Kroeger, A.K., Bender, S., Kunz, C.U. and Kieser, M. (2013) The Group-Based Social Skills Training SOSTA-FRA in Children and Adolescents with High Functioning Autism Spectrum Disorder-Study Protocol of the Randomised, Multi-Centre Controlled SOSTA-Net Trial. Trials, 14, 6. https://doi.org/10.1186/1745-6215-14-6

[39] Freitag, C.M., Jensen, K., Elsuni, L., Sachse, M., Herpertz-Dahlmann, B., Schulte-Ruther, M., Hanig, S., von Gontard, A., Poustka, L., Schad-Hansjosten, T., Wenzl, C., Sinzig, J., Taurines, R., Geissler, J., Kieser, M. and Cholemkery, H. (2016) Group-Based Cognitive Behavioural Psychotherapy for Children and Adolescents with ASD: The Randomized, Multicentre, Controlled SOSTA-Net Trial. Journal of Child Psychology and Psychiatry, 57, 596-605.

https://doi.org/10.1111/jcpp.12509

[40] Constantino, J.N. (2012) Social Responsiveness Scale, Second Edition (SRS-2). WPS Publisher.

[41] Achenbach, T.M. and Rescorla, L.A. (2001) Manual for the ASEBA School-Age Forms and Profiles. University of Vermont, Research Center for Children, Youth, and Families, Burlington, VT.

[42] Achenbach, T.M. and Rescorla, L.A. (2003) Manual for the ASEBA Adult Forms and Profiles. University of Vermont, Research Center for Children, Youth and Families, Burlington, VT.

[43] Glaser, B., Lothe, A., Chabloz, M., Dukes, D., Pasca, C., Redoute, J. and Eliez, S. (2012) Candidate Socioemotional Remediation Program for Individuals with Intellectual Disability. American Journal on Intellectual and Developmental Disabilities, 117, 368-383. https://doi.org/10.1352/1944-7558-117.5.368

[44] Cohen, J. (1969) Statistical Power Analysis for the Behavioral Sciences. Academic Press, New York.

[45] Tang, S.X., Yi, J.J., Calkins, M.E., Whinna, D.A., Kohler, C.G., Souders, M.C., McDonald-McGinn, D.M., Zackai, E.H., Emanuel, B.S., Gur, R.C. and Gur, R.E. (2014) Psychiatric Disorders in 22q11.2 Deletion Syndrome Are Prevalent but Undertreated. Psychological Medicine, 44, 1267-1277. https://doi.org/10.1017/S0033291713001669

[46] Fletcher-Watson, S., Petrou, A., Scott-Barrett, J., Dicks, P., Graham, C., O’Hare, A., Pain, H. and McConachie, H. (2016) A Trial of an $\mathrm{iPad}^{\mathrm{TM}}$ Intervention Targeting Social Communication Skills in Children with Autism. Autism, 20, 771-782. https://doi.org/10.1177/1362361315605624

[47] Harrell, W., Eack, S., Hooper, S.R., Keshavan, M.S., Bonner, M.S., Schoch, K. and Shashi, V. (2013) Feasibility and Preliminary Efficacy Data from a Computerized Cognitive Intervention in Children with Chromosome 22q11.2 Deletion Syndrome. Research in Developmental Disabilities, 34, 2606-2613. https://doi.org/10.1016/j.ridd.2013.05.009

[48] Pickard, H., Rijsdijk, F., Happe, F. and Mandy, W. (2017) Are Social and Communication Difficulties a Risk Factor for the Development of Social Anxiety? Journal of the American Academy of Child and Adolescent Psychiatry, 56, 344-351. e3. https://doi.org/10.1016/j.jaac.2017.01.007

[49] Wray, E., Shashi, V., Schoch, K., Curtiss, K. and Hooper, S.R. (2013) Discrepancies in Parent and Teacher Ratings of Social-Behavioral Functioning of Children with Chromosome 22q11.2 Deletion Syndrome: Implications for Assessment. American Journal on Intellectual and Developmental Disabilities, 118, 339-352. https://doi.org/10.1352/1944-7558-118.5.339 


\section{Supplementary Files}

Table S1. Baseline characteristics of study participants.

\begin{tabular}{|c|c|c|c|c|}
\hline Group membership & Participant & Status & $\begin{array}{l}\text { PPVT } \\
\text { score }\end{array}$ & $\begin{array}{l}\text { Raven's PM test } \\
\text { (\% correct answers) }\end{array}$ \\
\hline \multirow{5}{*}{$\begin{array}{c}\text { Group } 1 \\
\text { (Age: } 11-16 ; 4 \text { females and } 1 \text { male) }\end{array}$} & $\mathrm{P} 1$ & Completed trial & 107 & 48 \\
\hline & $\mathrm{P} 2$ & Completed trial & 91 & 68 \\
\hline & P3 & Completed trial & 59 & 38 \\
\hline & $\mathrm{P} 4$ & Completed trial & 112 & 46 \\
\hline & P5 & Dropout & 109 & 45 \\
\hline \multirow{4}{*}{$\begin{array}{c}\text { Group } 2 \\
\text { (Age: } 11-16 ; 3 \text { females and } 1 \text { male) }\end{array}$} & P6 & Completed trial & 93 & 45 \\
\hline & P7 & Completed trial & 95 & 53 \\
\hline & P8 & Completed trial & 76 & 43 \\
\hline & P9 & Completed trial & 107 & 65 \\
\hline \multirow{4}{*}{$\begin{array}{c}\text { Group } 3 \\
\text { (Age: } 20-22 ; 4 \text { females) }\end{array}$} & $\mathrm{P} 10$ & Completed trial & 89 & 73 \\
\hline & P11 & Completed trial & 89 & 48 \\
\hline & P12 & Completed trial & 111 & 71 \\
\hline & P13 & Excluded & 120 & 60 \\
\hline \multirow{4}{*}{$\begin{array}{c}\text { Group } 4 \\
\text { (Age: } 19-26 ; 3 \text { females and } 1 \text { male) }\end{array}$} & P14 & Completed trial & 120 & 40 \\
\hline & P15 & Completed trial & 100 & 56 \\
\hline & P16 & Completed trial & 58 & 25 \\
\hline & P17 & Completed trial & 89 & 15 \\
\hline \multirow{4}{*}{$\begin{array}{c}\text { Group } 5 \\
\text { (Age: } 13-14 ; 4 \text { males) }\end{array}$} & P18 & Completed trial & 77 & 50 \\
\hline & P19 & Completed trial & 101 & 63 \\
\hline & $\mathrm{P} 20$ & Completed trial & 111 & 86 \\
\hline & $\mathrm{P} 21$ & Dropout & 109 & 80 \\
\hline
\end{tabular}

